\title{
Salivary fluoride concentration following toothbrushing with and without rinsing: a randomised controlled trial
}

\author{
Marwah M. Albahrani ${ }^{1,3}$, Asma Alyahya ${ }^{2}$, Muawia A. Qudeimat ${ }^{2,4^{*}}$ and K. Jack Toumba ${ }^{2,3}$
}

\begin{abstract}
Background: Caries prevalence has declined significantly since the introduction of fluoridated toothpaste. There have been several developments regarding specific active fluoride ingredients but not enough evidence to support one over the other. The purpose of this double-blind randomized controlled trial was to compare salivary fluoride concentrations of different fluoride formulations in the form of toothpaste with and without post-brushing water rinsing in adults.
\end{abstract}

Methods: The study included 120 participants who were randomly assigned to one of 12 groups (10 participants/ group). The toothpaste formulas investigated included (1) fluoride-free (0 ppmF); (2) sodium fluoride (1450 ppmF); (3) sodium monofluorophosphate (1450 ppmF); (4) sodium fluoride and monofluorophosphate combined (1450 ppmF); (5) stannous fluoride and sodium fluoride combined (1450 ppmF); and (6) amine fluoride (1400 ppmF). Block randomisation was used to assign each participant to one of the 12 groups. Participants brushed with $1.0 \mathrm{~g}$ of one of the six different toothpaste formulations either with or without post-brushing water rinsing. Saliva was collected at six different times (baseline and at 1, 15, 30, 60, and 90 min/s post-brushing). Samples were analysed using a fluoride ionspecific sensitive electrode connected to an ion analyser.

Results: The demographic characteristics of the participants were not significantly different among the groups $(P>0.05)$. Time, toothpaste formulation, and post-brushing rinsing routines had significant effects on saliva fluoride retention $(P<0.05)$. Amine fluoride-containing toothpaste was the only formula that showed statistically significantly higher concentrations of salivary fluoride at $90 \mathrm{~min}$ in both the rinsing and non-rinsing groups. Sodium monofluorophosphate toothpaste did not result in a significant difference compared to the control group at any time point, in both rinsing and non-rinsing groups.

Conclusions: Based on the results from this study, no rinsing after toothbrushing in adults can be recommended when sodium monofluorophosphate containing toothpaste formula is used. It also concludes that amine fluoride resulted in a significantly higher saliva fluoride concentration at $90 \mathrm{~min}$ in both the rinsing and non-rinsing groups compared to other fluoride toothpaste formulations.

Registry: Protocol Registration and Results System (ClinicalTrials.gov).

Clinical trial registration number: NCT02740803 (15/04/2016).

\footnotetext{
${ }^{*}$ Correspondence: muawia.qudeimat@ku.edu.kw

${ }^{4}$ Faculty of Dentistry, Kuwait University, PO Box: 24923, Safat 13110,

Kuwait

Full list of author information is available at the end of the article
}

(C) The Author(s) 2022. Open Access This article is licensed under a Creative Commons Attribution 4.0 International License, which permits use, sharing, adaptation, distribution and reproduction in any medium or format, as long as you give appropriate credit to the original author(s) and the source, provide a link to the Creative Commons licence, and indicate if changes were made. The images or other third party material in this article are included in the article's Creative Commons licence, unless indicated otherwise in a credit line to the material. If material is not included in the article's Creative Commons licence and your intended use is not permitted by statutory regulation or exceeds the permitted use, you will need to obtain permission directly from the copyright holder. To view a copy of this licence, visit http://creativecommons.org/licenses/by/4.0/. The Creative Commons Public Domain Dedication waiver (http://creativeco mmons.org/publicdomain/zero/1.0/) applies to the data made available in this article, unless otherwise stated in a credit line to the data. 
Keywords: Fluoride toothpaste, Rinsing, Controlled clinical trial, Adults

\section{Introduction}

Dental caries is the most prevalent chronic disease worldwide. One of the widely accepted cost-effective methods of caries prevention is toothbrushing with fluoridated toothpaste. This method of delivering high-dose fluoride over a low-frequency regimen has proven its effectiveness in reducing the incidence of caries [1-4]. Systematic reviews and meta-analyses have confirmed the benefit of 1000-1500 ppm F-containing toothpaste to achieve caries prevention [5-7].

Fluoride-containing toothpaste is available in various chemical compositions and formulations. Amine fluoride $(\mathrm{AmF})$, sodium fluoride $(\mathrm{NaF})$, sodium monofluorophosphate $\left(\mathrm{Na}_{2} \mathrm{FPO}_{3}\right)$, and stannous fluoride $\left(\mathrm{SnF}_{2}\right)$ are the main active fluoride ingredients available in toothpastes. Clinical trials suggested the superiority of $\mathrm{NaF}$ composition over $\mathrm{SnF}_{2}$ and $\mathrm{Na}_{2} \mathrm{FPO}_{3}$ favouring $\mathrm{NaF}$ containing toothpaste [8-10]. Others suggested that $\mathrm{AmF}$ toothpaste resulted in higher salivary fluoride concentrations and therefore, marked remineralization of caries compared to $\mathrm{NaF}$ and $\mathrm{Na}_{2} \mathrm{FPO}_{3}$ containing toothpastes [11-14].

Post-brushing rinsing is an area of interest for many researchers exploring the anti-caries effectiveness of fluoride toothpastes. Post-brushing rinsing and the availability and rate of fluoride clearance from the oral cavity were investigated in several studies $[12,13,15,16]$. Rinsing post-brushing was found to result in significantly lower salivary fluoride concentrations compared to non-rinsing groups $[12,13,16,17]$. However, it has been concluded that there are no high-quality studies to support the comparative effectiveness of one active fluoride toothpaste formula over the other with or without post-brushing mouth rinsing [18]. Many previous clinical trials that investigated this subject had methodological limitations, including (1) inclusion and exclusion criteria were not clearly described $[9,11-13,16],(2)$ sample size calculations not performed [9, 11-13, 16, 17], (3) lack of randomisation $[9,11,17]$, and (4) examiners were not blinded to the intervention group [11, 17]. Therefore, the aim of this study was to conduct a randomised double-blind clinical trial to compare the salivary fluoride concentrations following toothbrushing with different fluoride toothpaste formulations with and without post-brushing water rinsing. The null hypotheses were: 1 . Toothpaste formulations with similar fluoride concentrations have no significant differences in terms of salivary concentrations of fluoride when measured at different time intervals; 2 . There are no significant differences between post-brushing rinsing and non-rinsing regarding salivary fluoride concentrations for the tested toothpaste formulations.

\section{Materials and methods}

This was a double-blind randomized controlled trial (RCT). Ethical approval was obtained from the Yorkshire and The Humber-Sheffield Research Ethics Committee (REC reference number 16/YH/0015). The trial protocol was registered with ClinicalTrials.gov (NCT02740803-15/04/2016).

Sample size calculations were performed using Power Analysis and Sample Size Software (version 11.0, NCSS Statistical Software, Kaysville, Utah, USA). The study aimed to test 12 groups; each group was tested at 6 different time intervals. For this study, the confidence intervals were set at $95 \%$, with $100 \%$ power. Sample size calculations were performed using raw data from a previous study [13]. A sample of at least three participants was needed for each group to achieve significant differences. It was decided to increase the final number of participants to 10 participants in each group, giving a total number of at least 120 participants. A circular email with an invitation to participate in the study was sent along with the recruitment flyer, the information sheet, and the consent sheet to students across the University of Leeds every two months starting from September 2016 until April 2017. Written consent was obtained from each participant.

To be included in the study, participants had to: 1 . be adults with American Society of Anaesthesiologists (ASA) grades I or II; and 2. have a resting salivary flow rate of $0.1 \mathrm{ml} /$ minute or more. Participants were excluded if they were: 1 . edentulous; 2 . allergic to any of the materials used in the study; 3 . incapable of fasting for four hours; 4. unable of retaining the toothpaste following brushing; or 5 . if they had orthodontic braces.

Block randomisation was used to assign participation numbers (1-120) to the participants in the groups (1-12) [https://www.randomlists.com/team-generator]. trained research dental assistant randomised the toothpaste formulations with and without rinsing to the groups (1-12) using the same website. Then, she concealed the toothpaste tubes and labelled them. The participants and the principal investigator were blinded to the toothpaste formula. In addition, the principal investigator (who carried out the statistical analysis) was blinded to the rinsing methods.

The clinical examination and the research trial were undertaken at the Dental Translational and Clinical 
Research Unit at the University of Leeds, UK. The World Health Organization (WHO) criteria for Decayed, Missing due to caries, and Filled Teeth in the permanent teeth (DMFT), and Decayed, Missing due to caries, and Filled Surfaces in the permanent teeth (DMFS) scoring were followed. Teeth were also visually examined for the presence or absence of supra-gingival calculus. No aiding tools were used to detect small traces of calculus or subgingival calculus. The interventions were to brush with one of the following six different toothpaste formulations:

1. Control group (fluoride-free toothpaste): Kingfisher Natural Toothpaste ${ }^{\circledR}$ Fennel-fluoride free-100 ml (Kingfisher Toothpaste, Norwich, UK).

2. Sodium fluoride toothpaste (1450 ppmF): Colgate Total ${ }^{\circledR}$ Original $\mathrm{Care}^{\mathrm{TM}}-125 \mathrm{ml}$ (Colgate-Palmolive, Surrey, UK).

3. Sodium monofluorophosphate (1450 ppmF): Colgate Sensitive ${ }^{\circledR}$ Pro-Relief ${ }^{\mathrm{TM}}$ Extra strength-75 ml (Colgate-Palmolive, Surrey, UK).

4. Sodium fluoride $(450 \mathrm{ppmF})$ and monofluorophosphate $(1000 \mathrm{ppmF})$ combined: Colgate ${ }^{\circledR}$ Cavity Protection $^{\mathrm{TM}}-75 \mathrm{ml}$ (Colgate-Palmolive, Surrey, UK).

5. Stannous fluoride (1100 ppmF) and sodium fluoride (350 ppmF) combined: Oral-B ${ }^{\circledR}$ Pro-Expert ${ }^{\mathrm{TM}}-75 \mathrm{ml}$ (Procter \& Gamble, Yorkshire, UK).

6. Amine fluoride (1400 ppmF): Elmex ${ }^{\circledR}$ Protezione Carie-75 ml (Colgate-GABA; Switzerland)

All participants were instructed to refrain from brushing their teeth on the day of sample collection (the last time they could brush their teeth was the night before), and fast for at least two hours before their appointment and throughout the entire appointment. On the day of the experiment, each participant was asked to drool (unstimulated saliva sample) into a $15 \mathrm{ml}$ sterile tube for two minutes to determine the salivary flow rate and the suitability of the participant to be included in the study. This sample was also used to determine the salivary fluoride concentration at baseline (pre-brushing sample). Participants were then asked to brush with a pre-weighed toothpaste $(1.0 \mathrm{~g})$ of one of 6 different fluoride toothpaste formulations for two full minutes. A timer was used to record the start and finish times of the brushing.

Depending on which group they were in, participants were either asked to spit the excess toothpaste and not rinse their mouth for the entire appointment or to rinse their mouth immediately following toothbrushing with $10 \mathrm{ml}$ of distilled water for five seconds. After brushing, unstimulated saliva samples were collected five times at the following time intervals: $1,15,30,60$, and $90 \mathrm{~min}(\mathrm{~s})$. Each saliva sample was collected in a pre-labelled test tube with the aid of a single-use funnel. Each sample was collected over two minutes. The brushing, rinsing, and collection of the saliva samples were supervised by a research assistant.

Each saliva sample tube was labelled with the participant's screening number, date of collection, and time interval. Saliva samples were preserved in the laboratory freezer (-18 degrees Celsius) until they were analysed. The total duration of freezing the saliva samples did not exceed three months. On the day of the analysis, saliva sample tubes were taken out of the freezer two hours before the analysis. Equal parts of saliva samples and lowlevel Total Ionic Strength Adjustment Buffering solution (TISAB II) with cyclohexylenedinitrilotetraacetate (CDTA) were mixed in a sterile test tube. Fluoride concentrations were measured using a calibrated ion-specific sensitive electrode (Orion ${ }^{\mathrm{TM}}$ Model 9609BNWP, Thermo Fisher Scientific, Cambridgeshire, UK) connected to an ion analyser. Calibration of the fluoride ion-selective combination electrode was performed prior to sample measurement. Manufacturer instructions were followed to perform direct calibration using $0.01,0.1,1.0,10,100$, and $1000 \mathrm{ppm}$ fresh standard fluoride solutions mixed with equal parts of low-level TISAB with CDTA. As per the manufacturer's instructions, the resulting slope value for the calibration process should be between -54.0 and $-60 \mathrm{mV}$ when the standards are between $20-25{ }^{\circ} \mathrm{C}$. Recalibration was performed every two hours as per the manufacturer's instructions. Recalibration of the electrode was performed when the reading of the values of the fluoride standards had changed by $2 \%$. After each measurement session, the samples were safely disposed of as per the local protocols of the University of Leeds laboratories.

\section{Statistical analysis}

The primary outcome was measuring salivary fluoride concentrations at baseline and post-brushing at 1, 15, 30, 60 , and $90 \mathrm{~min}$ with and without rinsing. Statistical analyses were performed using the Statistical Package for the Social Sciences (SPSS) software (version 23.0, IBM Corp., Armonk, NY, USA). Prior to data analysis of salivary fluoride concentrations, missing data were replaced by multiple imputations. Before the replacement of missing data, pattern analysis was performed to investigate whether the missing data followed a certain pattern or a random arrangement. The predictor effects were considered to be statistically significant at $\leq 5 \%$ level.

Mauchly's sphericity test was used to validate the repeated measures analysis of variance (ANOVA). Twoway mixed ANOVA with Tukey's post-hoc test and Bonferroni correction were used for the data analysis of fluoride concentrations within the different groups at 
the different time intervals and within individual groups comparing rinsing and non-rinsing groups.

\section{Results}

Of 230 individuals considered for participation, 124 were invited to attend the screening visit. Four subjects were excluded because they did not meet the inclusion criteria. In total, 120 participants completed the study: 10 in each of the 12 study groups. Figure 1 represents the Consolidated Standards of Reporting Trials (CONSORT) flow diagram of this randomised trial.

Baseline demographics for the participants in both study groups are presented in Table 1 . Age of participants ranged between $18-60$ years (mean $=27.25$ yrs., $\mathrm{SD}=7.64$ yrs.) with no statistically significant interaction found between the age of participants and the fluoride concentration at baseline $(\mathrm{F}=0.97, P=0.52$, partial Eta squared $=0.21)$. The majority $(66 \%)$ of participants were females. Salivary fluoride concentrations at baseline were not statistically significantly different between females and males (mean difference $=0.20 \mathrm{ppmF}, \mathrm{SE}=0.52$, $P=0.71)$.

For all participants, 85 (71\%) did not have clinically visible caries. Salivary fluoride concentrations at baseline in caries-free participants were not significantly different from caries-active participants (mean difference $=0.39 \mathrm{ppmF}, \mathrm{SE}=0.54, P=0.47$ ). No significant interaction was found between DMFT scores and salivary fluoride concentrations $(\mathrm{F}=0.42, P=0.42$, partial Eta squared $=0.07)$. No significant interaction was

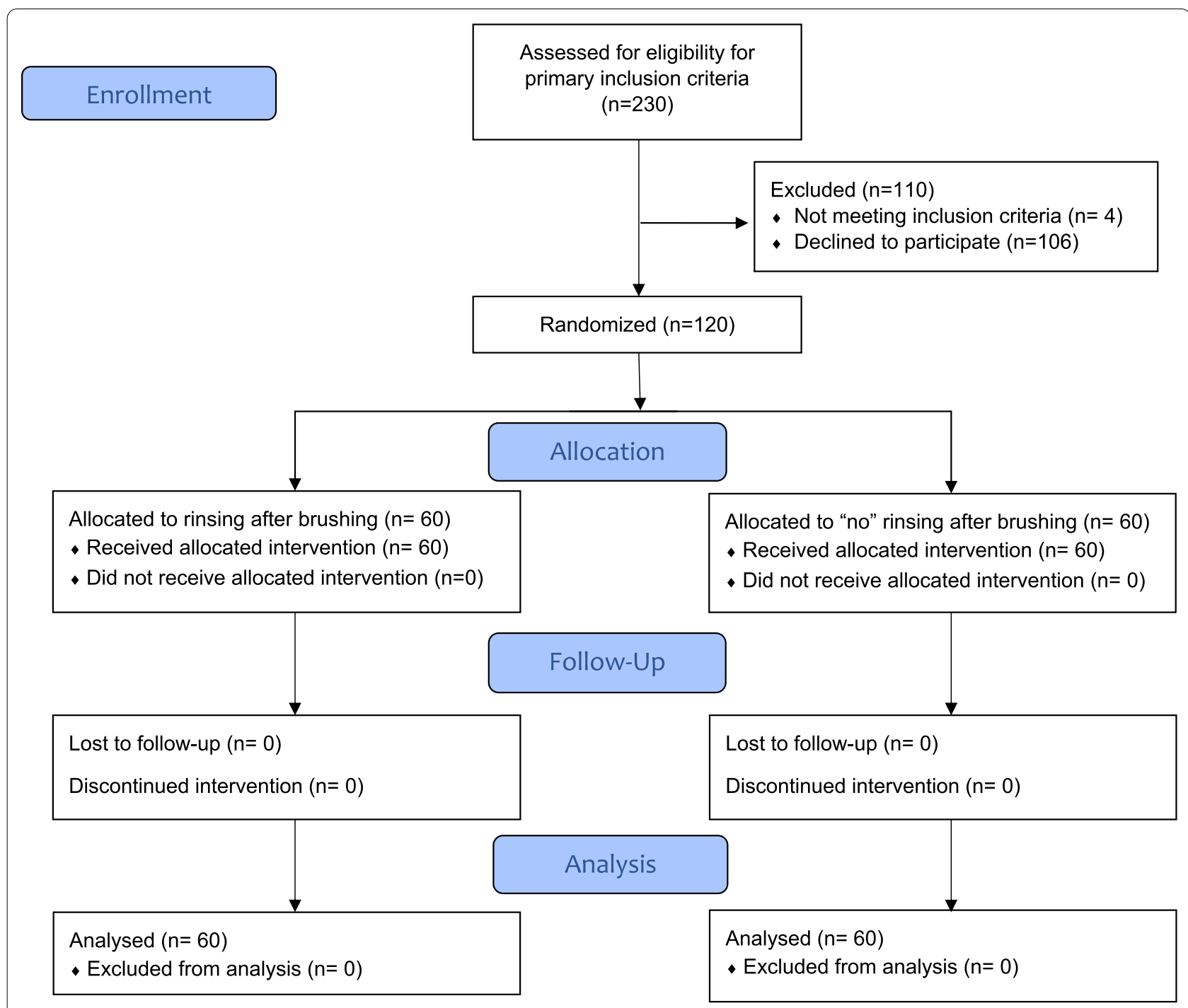

Fig. 1 Flowchart showing the selection of the study population 
Table 1 Baseline demographic and clinical characteristics for each group

\begin{tabular}{llll}
\hline Variable & Non-rinsing group & Rinsing group & Total \\
\hline Sex & & & $P$ \\
$\quad$ Female (\%) & $42(70)$ & $37(62)$ & $79(66)$ \\
$\quad$ Male (\%) & $18(30)$ & $23(38)$ & $41(34)$ \\
Age & & & $18-60$ \\
$\quad$ Range in years & $18-58$ & $18-60$ & $27.25(0.70)$ \\
Mean in years (SE) & $27.22(1.03)$ & $27.28(0.95)$ & 4.22 \\
Caries Experience (mean) & & & $0.74(5.18)$ \\
DMFT (SD) & $4.78(5.47)$ & $4.70(4.91)$ & $0.77(2.03)$ \\
DT (SD) & $0.60(2.29)$ & $0.93(1.73)$ & $3.17(0.08)$ \\
MT (SD) & $0.22(1.18)$ & $0.12(0.05)$ & $8.05(16.96)$ \\
FT (SD) & $3.97(4.19)$ & $3.65(3.75)$ & $0.91(2.74)$ \\
DMFS (SD) & $8.48(16.89)$ & $7.62(9.52)$ & $0.81(4.19)$ \\
DS (SD) & $0.73(3.17)$ & $1.08(2.23)$ & $6.93(9.58)$ \\
MS (SD) & $1.05(5.65)$ & $0.57(1.83)$ & 0.37 \\
FS (SD) & $6.70(11.31)$ & $5.97(7.55)$ & 0.53 \\
Calculus & & & 0.66 \\
No (\%) & $43(72)$ & $44(73)$ & 0.73 \\
Yes (\%) & $17(28)$ & $16(28)$ & 0.49 \\
\hline
\end{tabular}

found between DT scores and salivary fluoride concentrations $(\mathrm{F}=1.01, P=0.42$, partial Eta squared $=0.05)$; between MT scores and salivary fluoride concentrations $(\mathrm{F}=0.42, P=0.74$, partial Eta squared $=0.01)$; or FT scores and salivary fluoride concentrations $(\mathrm{F}=0.42$, $P=0.44$, partial Eta squared $=0.06$ ). Also, no significant interaction was found between DMFS scores and salivary fluoride concentrations $(\mathrm{F}=0.55, P=0.96$, partial Eta squared $=0.14$ ). No significant interaction was found between DS scores and salivary fluoride concentrations $(\mathrm{F}=0.72, P=0.66$, partial Eta squared $=0.05)$; MS scores and salivary fluoride concentrations $(\mathrm{F}=0.33, P=0.86$, partial Eta squared $=0.01)$; or FS scores and salivary fluoride concentrations $(\mathrm{F}=0.76, P=0.77$, partial Eta squared $=0.16$ ).

For all the participants, 87 (73\%) did not have clinically visible calculus. The salivary fluoride concentration at baseline was not statistically significant between participants with calculus and those without calculus (mean difference $=0.08 \mathrm{ppmF}, \mathrm{SE}=0.56, P=0.89$ ).

There were four missing values of salivary fluoride concentration of two participants due to technical and/ or human error. The data did not follow a normal distribution and significant outliers were noticed across several time intervals. Mauchly's test of sphericity indicated that the assumption of sphericity was violated for the two-way interaction, approximate chi-squared value $=2635.75(P<0.0005)$. Therefore, estimates from Greenhouse-Geisser corrections were used to assess the interaction between the time and the group. There was a statistically significant two-way interaction between the time and the group on the salivary fluoride concentration $(\mathrm{F}(11.16-109.54)=11.70, P<0.0005$, partial Eta squared $=0.54)$. This meant that the salivary fluoride concentration changed significantly over time depending on which group the participants were in.

There was no statistically significant difference in salivary fluoride concentrations between the non-rinsing groups at baseline $(\mathrm{F}=2.07, P=0.08$, partial Eta squared $=0.16$ ). There was a statistically significant effect of time on salivary fluoride concentrations for all nonrinsing groups $(P<0.0005)$ except for the control group $(P=0.12)$.

There was no statistically significant difference in salivary fluoride concentrations between the rinsing groups at baseline $(F=1.59, P=0.18$, partial Eta squared $=0.13)$. There was a statistically significant effect of time on salivary fluoride concentrations for all rinsing groups $(P<0.0005)$.

Table 2 demonstrates the mean fluoride concentration (ppmF) for all fluoride toothpaste formulas at different time intervals between rinsing and non-rinsing groups.

The only two formulas that showed a statistically significant difference at one minute between the rinsing and non-rinsing groups were $\mathrm{AmF}$ and $\mathrm{NaF}$ containing toothpaste. For $\mathrm{Na}_{2} \mathrm{FPO}_{3}$, statistically significantly higher fluoride concentrations were seen in the non-rinsing groups at baseline, 15, 30, and $90 \mathrm{~min}$.

Comparisons between the different fluoride toothpaste formulas for the non-rinsing and rinsing groups 
Table 2 Comparisons between the mean fluoride concentration (ppmF) at different time intervals between rinsing and non-rinsing groups

\begin{tabular}{|c|c|c|c|c|c|c|c|}
\hline \multirow[t]{2}{*}{ Group } & \multirow[t]{2}{*}{ Rinsing Status } & \multicolumn{6}{|c|}{ Mean fluoride concentration (SD) at each study interval } \\
\hline & & Baseline & $1 \mathrm{~min}$ & $15 \mathrm{~min}$ & $30 \mathrm{~min}$ & $60 \mathrm{~min}$ & $90 \mathrm{~min}$ \\
\hline \multirow[t]{4}{*}{ Control (fluoride-free) } & NR & $0.106(0.154)$ & $0.032(0.193)$ & $0.050(0.071)$ & $0.041(0.053)$ & $0.039(0.060)$ & $0.041(0.056)$ \\
\hline & $\mathrm{R}$ & $0.129(0.120)$ & $0.037(0.038)$ & $0.039(0.049)$ & $0.023(0.024)$ & $0.031(0.048)$ & $0.020(0.030)$ \\
\hline & F-test & 0.135 & 0.120 & 0.178 & 0.892 & 0.133 & 1.085 \\
\hline & $P$-value & 0.718 & 0.733 & 0.678 & 0.357 & 0.720 & 0.311 \\
\hline \multirow[t]{4}{*}{ Amine Fluoride (AmF) } & $N R$ & $0.173(0.205)$ & $33.760(17.507)$ & $2.784(2.214)$ & $1.216(1.044)$ & $0.500(0.365)$ & $0.324(0.221)$ \\
\hline & $R$ & $0.059(0.058)$ & 16.865 (9.286) & $1.650(1.169)$ & $0.561(0.414)$ & $0.312(0.295)$ & $0.174(0.160)$ \\
\hline & F-test & 2.900 & 7.268 & 3.395 & 3.133 & 1.614 & 3.040 \\
\hline & $P$-value & 0.106 & $0.015^{*}$ & 0.082 & 0.169 & 0.220 & 0.098 \\
\hline \multirow[t]{4}{*}{ Sodium Fluoride (NaF) } & $N R$ & $0.048(0.025)$ & $35.500(18.351)$ & $3.322(2.504)$ & $0.787(0.523)$ & $0.299(0.229)$ & $0.158(0.095)$ \\
\hline & $\mathrm{R}$ & $0.063(0.043)$ & $15.104(9.497)$ & $1.701(0.856)$ & $0.452(0.210)$ & $0.213(0.104)$ & $0.138(0.096)$ \\
\hline & F-test & 0.969 & 9.743 & 3.748 & 3.546 & 1.159 & 0.206 \\
\hline & $P$-value & 0.338 & $0.006^{*}$ & 0.069 & 0.076 & 0.296 & 0.655 \\
\hline \multirow[t]{4}{*}{ Sodium Monofluorophosphate $\left(\mathrm{Na}_{2} \mathrm{FPO}_{3}\right)$} & $N R$ & $0.172(0.143)$ & $12.775(4.871)$ & $1.905(1.281)$ & $0.537(0.371)$ & $0.180(0.101)$ & $0.113(0.062)$ \\
\hline & $\mathrm{R}$ & $0.046(0.043)$ & $8.976(4.519)$ & $0.867(0.578)$ & $0.260(0.137)$ & $0.107(0.058)$ & $0.058(0.029)$ \\
\hline & F-test & 7.109 & 3.269 & 5.461 & 4.896 & 3.961 & 6.705 \\
\hline & $P$-value & $0.016^{*}$ & 0.087 & $0.031^{*}$ & $0.040^{*}$ & 0.062 & $0.019^{*}$ \\
\hline \multirow{4}{*}{$\begin{array}{l}\text { Sodium Fluoride and Sodium Monofluoro- } \\
\text { phosphate }\left(\mathrm{NaF} \& \mathrm{Na}_{2} \mathrm{FPO}_{3}\right)\end{array}$} & NR & $0.046(0.023)$ & $18.118(10.066)$ & $1.512(1.452)$ & $0.369(0.292)$ & $0.149(0.104)$ & $0.105(0.086)$ \\
\hline & $\mathrm{R}$ & $0.078(0.080)$ & $12.285(6.486)$ & $1.356(0.849)$ & $0.443(0.459)$ & $0.186(0.259)$ & $0.100(0.120)$ \\
\hline & F-test & 1.395 & 2.373 & 0.086 & 0.184 & 0.175 & 0.016 \\
\hline & $P$-value & 0.253 & 0.141 & 0.773 & 0.673 & 0.681 & 0.900 \\
\hline \multirow{4}{*}{$\begin{array}{l}\text { Stannous Fluoride and Sodium Fluoride } \\
\left(\mathrm{SnF}_{2} \& \mathrm{NaF}\right)\end{array}$} & $N R$ & $0.153(0.117)$ & 21.919 (11.677) & 1.054 (0.673) & $0.272(0.154)$ & $0.116(0.058)$ & $0.071(0.034)$ \\
\hline & $\mathrm{R}$ & $0.087(0.068)$ & $17.710(9.433)$ & $2.245(1.800)$ & $0.506(0.342)$ & $0.175(0.121)$ & $0.078(0.042)$ \\
\hline & F-test & 2.368 & 0.786 & 3.844 & 4.122 & 1.935 & 0.195 \\
\hline & $P$-value & 0.141 & 0.387 & 0.066 & 0.057 & 0.181 & 0.664 \\
\hline
\end{tabular}

$N R$, non rinsing; $R$, rinsing

*Statistically significant $(P \leq 0.05)$

Table 3 Mean differences (row-column) of fluoride concentration between toothpastes at one minute after brushing and without rinsing

\begin{tabular}{llllll}
\hline Toothpaste & Control & $\mathrm{AmF}$ & $\mathrm{NaF}$ & $\mathrm{Na}_{2} \mathrm{FPO}_{3}$ & $\begin{array}{l}\mathrm{NaF} \& \\
\mathrm{Na}_{2} \mathrm{FPO}_{3}\end{array}$ \\
\hline $\mathrm{AmF}$ & $33.73^{*}$ & & & & \\
$\mathrm{NaF}$ & $35.47^{*}$ & 1.74 & & & \\
$\mathrm{Na}_{2} \mathrm{FPO}_{3}$ & 12.74 & $-20.99^{*}$ & $-22.73^{*}$ & & \\
$\mathrm{NaF}_{2} \mathrm{Na}_{2} \mathrm{FPO}_{3}$ & $18.10^{*}$ & $-15.64^{*}$ & $-17.38^{*}$ & 5.34 & \\
$\mathrm{SnF}_{2} \& \mathrm{NaF}$ & $21.89^{*}$ & -11.84 & -13.58 & 9.14 & 3.80 \\
\hline
\end{tabular}

*Statistically significant $(P \leq 0.05)$

over three different time intervals $(1,15$, and $30 \mathrm{~min}$ ) are shown in Tables 3, 4, 5, 6, 7 and $8 . \mathrm{Na}_{2} \mathrm{FPO}_{3}$ was the only fluoride toothpaste formula that demonstrated no statistically significant difference compared to the control group (fluoride-free toothpaste) at all time intervals for both the non-rinsing and rinsing groups. In the
Table 4 Mean differences (row-column) of fluoride concentration between toothpastes at one minute after brushing and with rinsing

\begin{tabular}{lcrrrl}
\hline Toothpaste & Control & $\mathrm{AmF}$ & $\mathrm{NaF}$ & $\mathrm{Na}_{2} \mathrm{FPO}_{3}$ & $\begin{array}{l}\mathrm{NaF} \& \\
\mathrm{Na}_{2} \mathrm{FPO}_{3}\end{array}$ \\
\hline $\mathrm{AmF}$ & $16.83^{*}$ & & & & \\
$\mathrm{NaF}$ & $15.07^{*}$ & -1.76 & & & \\
$\mathrm{Na}_{2} \mathrm{FPO}_{3}$ & 8.94 & -7.90 & -6.13 & & \\
$\mathrm{NaF}_{2} \mathrm{Na}_{2} \mathrm{FPO}_{3}$ & $12.25^{*}$ & -4.58 & -2.82 & 3.31 & \\
$\mathrm{SnF}_{2} \& \mathrm{NaF}$ & $17.67^{*}$ & 0.85 & 2.61 & 8.73 & 5.43 \\
\hline
\end{tabular}

${ }^{*}$ Statistically significant $(P \leq 0.05)$

non-rinsing arm of the study, the highest statistically significant mean differences of fluoride concentration were reported for the $\mathrm{NaF}$ and the AmF groups compared to the control group at one-minute post-brushing (35.47 and $33.73 \mathrm{ppmF}$ respectively). 
Table 5 Mean differences (row-column) of fluoride concentration between toothpastes at $15 \mathrm{~min}$ after brushing and without rinsing

\begin{tabular}{llrlll}
\hline Toothpaste & Control & $\mathrm{AmF}$ & $\mathrm{NaF}$ & $\mathrm{Na}_{2} \mathrm{FPO}_{3}$ & $\begin{array}{l}\mathrm{NaF} \& \\
\mathrm{Na}_{2} \mathrm{FPO}_{3}\end{array}$ \\
\hline $\mathrm{AmF}$ & $2.73^{*}$ & & & & \\
$\mathrm{NaF}$ & $3.27^{*}$ & 0.54 & & & \\
$\mathrm{Na} \mathrm{FPO}_{3}$ & 1.85 & -0.88 & -1.42 & & \\
$\mathrm{NaF}_{2} \mathrm{Na}_{2} \mathrm{FPO}_{3}$ & 1.46 & -1.27 & -1.81 & -0.39 & \\
$\mathrm{SnF}_{2} \& \mathrm{NaF}$ & 1.00 & -1.73 & $-2.27^{*}$ & -0.85 & -0.46 \\
\hline
\end{tabular}

${ }^{*}$ Statistically significant $(P \leq 0.05)$

Table 6 Mean differences (row-column) of fluoride concentration between toothpastes at 15 min after brushing and with rinsing

\begin{tabular}{llrrrl}
\hline Toothpaste & Control & $\mathrm{AmF}$ & $\mathrm{NaF}$ & $\mathrm{Na}_{2} \mathrm{FPO}_{3}$ & $\begin{array}{l}\mathrm{NaF} \& \\
\mathrm{Na}_{2} \mathrm{FPO}_{3}\end{array}$ \\
\hline $\mathrm{AmF}$ & $1.61^{*}$ & & & & \\
$\mathrm{NaF}$ & $1.66^{*}$ & 0.05 & & & \\
$\mathrm{Na}_{2} \mathrm{FPO}_{3}$ & 0.83 & -0.78 & -0.83 & & \\
$\mathrm{NaF}_{2} \mathrm{Na}_{2} \mathrm{FPO}_{3}$ & 1.32 & -0.29 & -0.35 & 0.49 & \\
$\mathrm{SnF}_{2} \& \mathrm{NaF}$ & $2.21^{*}$ & 0.60 & 0.54 & $1.38^{*}$ & 0.89 \\
\hline
\end{tabular}

*Statistically significant $(P \leq 0.05)$

Table 7 Mean differences (row-column) of fluoride concentration between toothpastes at $30 \mathrm{~min}$ after brushing and without rinsing

\begin{tabular}{llllll}
\hline Toothpaste & Control & $\mathrm{AmF}$ & $\mathrm{NaF}$ & $\mathrm{Na}_{2} \mathrm{FPO}_{3}$ & $\begin{array}{l}\mathrm{NaF} \& \\
\mathrm{Na}_{2} \mathrm{FPO}_{3}\end{array}$ \\
\hline $\mathrm{AmF}$ & $1.81^{*}$ & & & & \\
$\mathrm{NaF}$ & $0.75^{*}$ & -0.43 & & & \\
$\mathrm{Na}_{2} \mathrm{FPO}_{3}$ & 0.50 & -0.68 & -0.25 & & \\
$\mathrm{NaFF}_{2} \mathrm{Na}_{2} \mathrm{FPO}_{3}$ & 0.33 & $-0.85^{*}$ & -0.42 & -0.17 & \\
$\mathrm{SnF}_{2} \& \mathrm{NaF}$ & 0.23 & $-0.94^{*}$ & -0.52 & -0.27 & -0.10 \\
\hline
\end{tabular}

* Statistically significant $(P \leq 0.05)$

Table 8 Mean differences (row-column) of fluoride concentration between toothpastes at 30 min after brushing and with rinsing

\begin{tabular}{|c|c|c|c|c|c|}
\hline Toothpaste & Control & $\mathrm{AmF}$ & $\mathrm{NaF}$ & $\mathrm{Na}_{2} \mathrm{FPO}_{3}$ & $\begin{array}{l}\mathrm{NaF} \& \\
\mathrm{Na}_{2} \mathrm{FPO}_{3}\end{array}$ \\
\hline $\mathrm{AmF}$ & $0.54^{*}$ & & & & \\
\hline $\mathrm{NaF}$ & $0.43^{*}$ & -0.10 & & & \\
\hline $\mathrm{Na}_{2} \mathrm{FPO}_{3}$ & 0.24 & -0.30 & -0.19 & & \\
\hline $\mathrm{NaF} \& \mathrm{Na}_{2} \mathrm{FPO}_{3}$ & $0.42^{*}$ & -0.12 & -0.01 & 0.18 & \\
\hline $\mathrm{SnF}_{2} \& \mathrm{NaF}$ & $0.49^{*}$ & -0.05 & 0.06 & 0.26 & 0.07 \\
\hline
\end{tabular}

${ }^{*}$ Statistically significant $(P \leq 0.05)$
At $60 \mathrm{~min}$, the mean difference of fluoride ranged between $0.01-0.28 \mathrm{ppmF}$ for all group comparisons in the rinsing groups and $0.03-0.46 \mathrm{ppmF}$ for all group comparisons in the non-rinsing groups. At this time interval, only the AmF containing toothpaste showed a significantly higher fluoride concentration (mean difference $=0.28 \mathrm{ppmF}$ ) compared to the control group in the rinsing arm of the study $(P<0.05)$. On the other hand, compared to the control, $\mathrm{Na}_{2} \mathrm{FPO}_{3}, \mathrm{NaF} \& \mathrm{Na}_{2} \mathrm{FPO}_{3}$, and $\mathrm{SnF}_{2} \& \mathrm{NaF}$ groups, the $\mathrm{AmF}$ group demonstrated a statistically significant higher saliva fluoride retention (mean difference $=0.32-0.38 \mathrm{ppmF}$ ) in the non-rinsing arm of the study $(P<0.05)$. All other between-group comparisons were not significant.

At $90 \mathrm{~min}$, the mean differences in fluoride concentrations ranged between $0.02-0.15 \mathrm{ppmF}$ for all group comparisons in the rinsing arm of the study, and 0.01$0.28 \mathrm{ppmF}$ for all group comparisons in the non-rinsing arm of the study. At this time interval, compared to the control group in both study arms, only AmF containing toothpaste showed statistically significantly higher concentrations (mean difference $=0.15$ and $0.28 \mathrm{ppmF}$ for the rinsing and non-rinsing groups, respectively) $(P<0.05)$. All other between-groups comparisons were not significant. Comparisons between the 12 different groups at different time intervals are presented in Fig. 2.

\section{Discussion}

Several high-quality review articles demonstrated the role of topical fluoride treatments in significantly reducing the development of new carious lesions [19]. Strong evidence was found associating the daily use of fluoride toothpaste to a significant reduction of caries in children [19]. However, the preventive benefits of fluoride toothpaste are seldom studied in adults who have a different oral environment due to the number of restorations and missing teeth, toothbrushing routines, and other salivary factors [20]. To our knowledge, this is the first double-blinded, randomised controlled study investigating salivary fluoride concentrations after brushing with five different toothpaste formulations with two post-brushing instructions in an adult population.

To combat caries, fluoride toothpaste should result in significantly elevated and sustained levels of fluoride in saliva, and the liquid and solid phases of the dental biofilm [21]. Interest in post-brushing routines as a potential determinant of fluoride levels in saliva and therefore the anti-caries effect of fluoride toothpaste unfolded as the understanding of the topical mechanism of action of fluoride grew and the importance of oral fluoride retention became a significant factor [22]. Using toothpaste with $1450 \mathrm{ppmF}$, the fluoride concentration in saliva was found to be $100 \mathrm{ppmF}$ during tooth brushing, which dropped to 


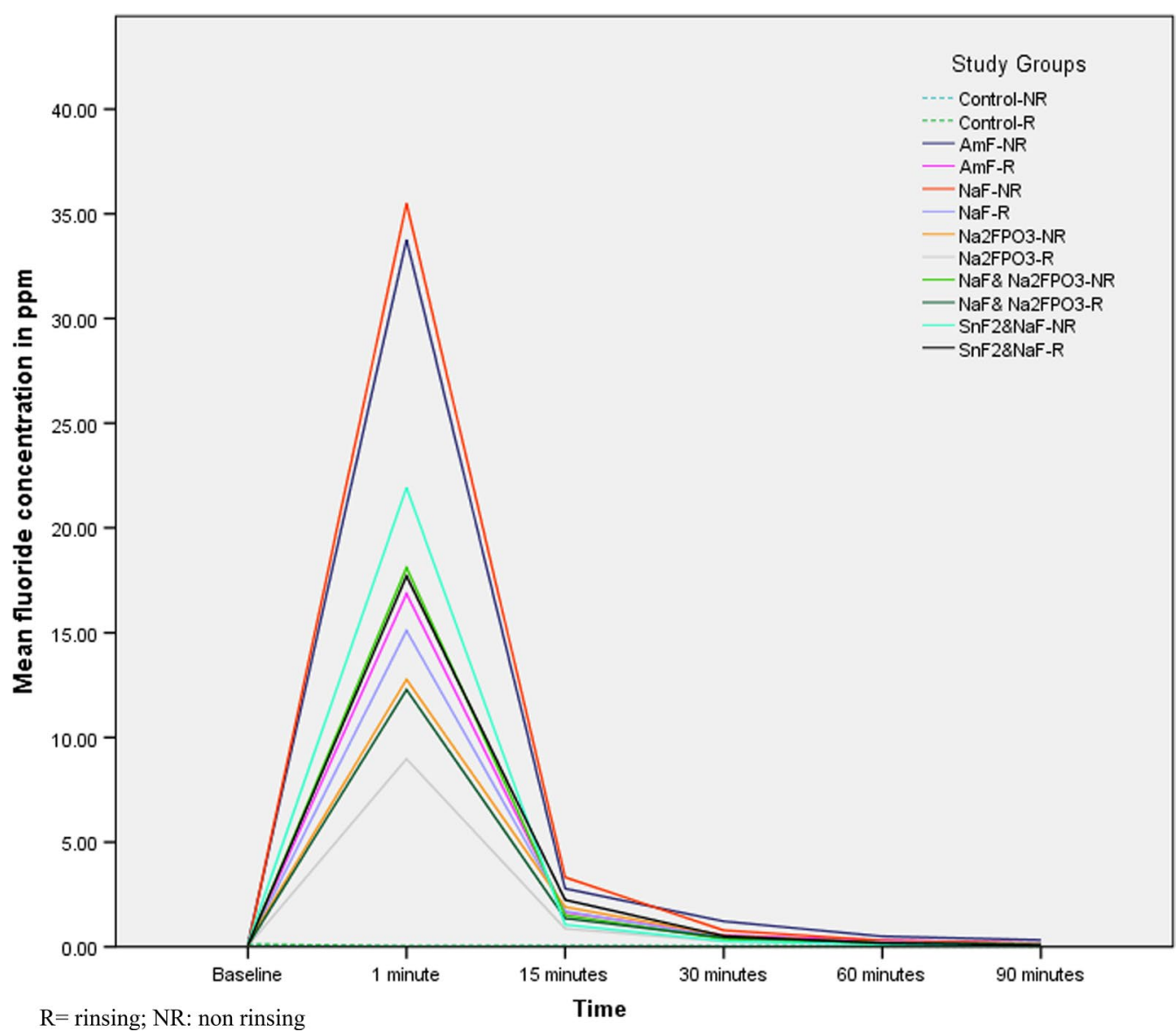

Fig. 2 Estimated marginal means of salivary fluoride concentrations (ppmF) for 12 groups at different time intervals with and without post-brushing rinsing. $R=$ rinsing; NR: non rinsing

less than $50 \mathrm{ppm}$ just after tooth brushing [23]. It was also observed that after brushing with fluoride toothpaste, salivary fluoride concentrations decreased in two distinct phases: an initial phase lasting 40-80 min and a second slow phase lasting several hours [17]. Naumova et al. [24] reported that the peak increase in salivary fluoride concentration immediately after brushing with $\mathrm{NaF}$ or AmF toothpaste lasted for $30 \mathrm{~min}$ and dropped to the baseline levels after six hours. In the current study, salivary fluoride concentration followed a similar pattern. The highest salivary fluoride concentration for all study groups was reported at one-minute post-brushing $(8.98-35.5 \mathrm{ppmF})$, which dropped to $0.06-0.32 \mathrm{ppmF}$ at $90 \mathrm{~min}$.

There is evidence in the literature that thorough rinsing after toothbrushing accelerates the elimination of fluoride from the oral cavity $[13,17,25]$. Post-brushing rinsing was found to significantly lower salivary fluoride concentrations when compared to non-rinsing groups $[12,13,16,19]$. On the other hand, a review by Twetman [19] concluded that evidence regarding the post-brushing practices was poor and conclusions could not be drawn.
Still, current guidelines discourage post-brushing rinsing, as this practice washes away the fluoride and reduces the caries preventive effect of the fluoridated toothpaste $[18,26]$. In the present study, a significant difference in salivary fluoride concentration between the rinsing and non-rinsing groups was only found in two groups (NaF and $\mathrm{AmF}$ ) at one minute and most of the time intervals for the $\mathrm{Na}_{2} \mathrm{FPO}_{3}$ group. All other time intervals for most toothpaste formulas showed no significant difference between the rinsing and non-rinsing groups. It has been shown that fluoride retention in the oral cavity is influenced by many factors, such as saliva clearance, fluoride concentration of toothpaste, amount of toothpaste, and water rinsing $[27,28]$. In the current study, factors like toothpaste formula, amount of toothpaste, and rinsing time and methods were standardised among the groups. However, the effects of factors like salivary clearance and fluoride reservoirs in the oral cavity of the participants were not accounted for.

Currently, there are multiple different fluoride formulations available on the market. No evidence was 
found relating a specific chemical formulation to caries prevention [18]. Bruun et al. [29] was one of the earliest studies that compared the concentrations of salivary fluoride after toothbrushing with $\mathrm{NaF}(500,1000$, and $1500 \mathrm{ppmF}$ ), and $\mathrm{Na}_{2} \mathrm{FPO}_{3}$ (500 and $1000 \mathrm{ppmF}$ ) toothpaste. The study claimed that the $\mathrm{Na}_{2} \mathrm{FPO}_{3}$ compound was subjected to rapid hydrolysis by bacterial phosphatase enzymes in saliva, which led to the rapid increase of fluoride ion concentration $10 \mathrm{~min}$ postbrushing with $\mathrm{Na}_{2} \mathrm{FPO}_{3}$ [29]. This was supported by trials that compared salivary fluoride levels post-brushing between $\mathrm{NaF}$ toothpaste $(1500 \mathrm{ppmF})$ and $\mathrm{Na}_{2} \mathrm{FPO}_{3}$ toothpaste $(1500 \mathrm{ppmF})[9,17]$. The study concluded that $\mathrm{NaF}$ toothpaste resulted in significantly higher fluoride retention when compared to $\mathrm{Na}_{2} \mathrm{FPO}_{3}$ toothpaste [9]. This is in agreement with the results reported from the present study, where salivary fluoride concentrations for the $\mathrm{Na}_{2} \mathrm{FPO}_{3}$ formula showed a high drop at $15 \mathrm{~min}$ in the rinsing and non-rinsing groups and without significant differences compared to the control group at any time interval. However, the combined $\mathrm{NaF}$ and $\mathrm{Na}_{2} \mathrm{FPO}_{3}$ toothpaste showed a significant increase in salivary fluoride concentration over an extended period compared to the $\mathrm{Na}_{2} \mathrm{FPO}_{3}$ group but not compared to the $\mathrm{NaF}$ only toothpaste group.

It has been shown that AmF toothpaste resulted in higher salivary fluoride concentrations compared to $\mathrm{NaF}$ and $\mathrm{Na}_{2} \mathrm{FPO}_{3}$ [11-13]. Issa and Toumba [13] conducted a randomised controlled trial to compare the salivary fluoride retention in vivo following brushing with different fluoride formulations and concentrations with and without water rinsing. They concluded that AmF toothpaste (1400 ppmF) resulted in the highest fluoride content of saliva without rinsing at $120 \mathrm{~min}$. The salivary fluoride content of $\mathrm{AmF}$ and $\mathrm{NaF}$ were still higher than baseline levels after $120 \mathrm{~min}$. The study did not express the results in terms of the difference in means but rather higher and lower fluoride concentration levels which makes it difficult to interpret whether any increase was likely to have influenced caries prevention. The present study agrees that AmF resulted in significantly higher salivary fluoride concentration for the longest period ( $90 \mathrm{~min}$ ), for both rinsing and non-rinsing groups when compared to the control groups. This could be explained by the alignment of AmF as the hydrophilic part is arranged closely to the enamel of the tooth, while the hydrophobic part is arranged on the outside [30].

Published clinical and laboratory studies demonstrate the efficacy of $\mathrm{SnF}_{2}$ in reducing bacterial growth and activity, as well as protection against plaque, gingivitis, and caries [31]. However, to date, no study has investigated the saliva clearance of fluoride from $\mathrm{SnF}_{2}$ containing toothpaste. In the current work, a toothpaste with a combination of $\mathrm{SnF}_{2}$ and $\mathrm{NaF}$ was used. In the non-rinsing group, there was a significant difference in salivary fluoride content compared to the control group only after one minute of toothbrushing. However, in the rinsing groups, the salivary fluoride retention was higher for the $\mathrm{SnF}_{2}$ and $\mathrm{NaF}$ group compared to the control group in the first $30 \mathrm{~min}$ after toothbrushing.

Finally, the increase in fluoride in the oral cavity does not need to be substantial to have an anti-caries effect: even a relatively small increase in fluoride levels (from $0.03 \mathrm{ppm}$ to $0.11 \mathrm{ppm}$ ) have been shown to enhance remineralisation, inhibit demineralisation of enamel and dentine, and reduce caries in the permanent dentition [32, 33].

This study is not without limitations. Firstly, to control the amount of water used for rinsing, the participants were asked to use a beaker of $10 \mathrm{ml}$ water to rinse after toothbrushing. An earlier study found higher caries increments in participants who used a beaker of water compared to those who used other methods for rinsing after toothbrushing [15]. Secondly, when comparing the different toothpaste products and formulas, this study did not consider other product-related factors including the compatibility of active and other agents in the toothpaste which could affect the substantivity of fluoride in the oral cavity [22]. Thirdly, Duckworth and Morgan [17] found that after brushing with fluoride toothpaste, salivary fluoride can be released in a slow phase that can last for several hours. They believed that this was due to fluoride released from an oral fluoride reservoir. In the current study, this was evident where at the beginning of the study, participants in all groups had fluoride at baseline ranging between 0.05 and $0.17 \mathrm{ppmF}$. It is possible that the results of this study might have been influenced by oral fluoride reservoirs.

\section{Conclusions}

Sodium monofluorophosphate containing toothpaste was the only formula that showed statistically significantly higher levels of fluoride in the non-rinsing group at 15-, 30- and 90-min time intervals compared to the rinsing group.

Compared to the control group, all fluoridated toothpastes were associated with higher salivary fluoride concentrations at the one-minute time interval, except for $\mathrm{Na}_{2} \mathrm{FPO}_{3}$ toothpaste.

AmF containing toothpaste was the only formula that showed statistically significantly higher concentrations of salivary fluoride at $90 \mathrm{~min}$ in both the rinsing and nonrinsing groups. 


\section{Acknowledgements}

The authors thank Mrs. G. Dukanovic for her outstanding assistance during all clinical sessions. We also appreciate all the participants in the current study. This study was conducted as part of M.M.A.'s Professional Doctorate of Paediatric Dentistry (DPaedDent) degree dissertation project at the University of Leeds.

\section{Authors' contributions}

All authors contributed to the present study. M.M.A. and K.J.T. contributed to the study conception and design. Material preparation and data collection were carried out by M.M.A. The analysis and interpretation of the data were performed by M.M.A., A.A., and M.A.Q., who also took the lead in writing the first draft of the manuscript. All authors commented on the previous versions of the manuscript. All authors read and approved the final manuscript.

\section{Funding}

None.

\section{Data availability}

All data generated or analysed during this study are included in this article. Further enquiries can be directed to the corresponding author.

\section{Declarations}

\section{Ethical approval and consent to participate}

This study complies with the guidelines for human studies and was conducted ethically in accordance with the World Medical Association Declaration of Helsinki. Written consent was received from each participant. The study protocol was approved by the Health Research Authority-Yorkshire and the Humber-Sheffield Research Ethics Committee, UK. With the trial registered in ClinicalTrials.gov (NCT02740803).

\section{Consent for publication}

Not applicable.

\section{Informed consent}

Informed consent was obtained from all individual participants included in the study.

\section{Competing interests}

Author M.M. Albahrani declares that she has no conflict of interest. Author A. Alyahya declares that she has no conflict of interest. Author M.A. Qudeimat declares that he has no conflict of interest. Author K.J. Toumba declares that he has no conflict of interest.

\section{Author details}

${ }^{1}$ Department of Paediatric Dentistry, Farwanyia Speciality Dental Centre, Farwanyia, Kuwait. 'Department of Developmental and Preventive Sciences, Kuwait University, Jabriyah, Kuwait. ${ }^{3}$ Department of Paediatric Dentistry, The University of Leeds School of Dentistry, Clarendon Way, Leeds LS2 9JT, West Yorkshire, UK. ${ }^{4}$ Faculty of Dentistry, Kuwait University, PO Box: 24923, Safat 13110, Kuwait.

Received: 12 October 2021 Accepted: 22 February 2022 Published online: 03 March 2022

\section{References}

1. Marinho VC, Higgins JP, Sheiham A, Logan S. Fluoride toothpastes for preventing dental caries in children and adolescents. Cochrane Database Syst Rev. 2003;(1):CD002278.

2. Marinho VCC. Cochrane reviews of randomized trials of fluoride therapies for preventing dental caries. Eur Arch Paediatr Dent. 2009;10(3):183-91.

3. Levine RS. What concentration of fluoride toothpaste should dental teams be recommending? Evid Based Dent. 2019;20(3):74-5.

4. Khan IM, Mani SA, Doss JG, Danaee M, Kong LYL. Pre-schoolers'tooth brushing behaviour and association with their oral health: a cross sectional study. BMC Oral Health. 2021;21(1):283.
5. Twetman S, et al. Caries-preventive effect of fluoride toothpaste: a systematic review. Acta Odontol Scand. 2003;61(6):347-55.

6. Smaïl-Faugeron V, Fron-Chabouis H, Courson F. Methodological quality and implications for practice of systematic Cochrane reviews in pediatric oral health: a critical assessment. BMC Oral Health. 2014;14:35.

7. Walsh T, Worthington HV, Glenny AM, Marinho VC, Jeroncic A. Fluoride toothpastes of different concentrations for preventing dental caries. Cochrane Database Syst Rev. 2019;3(3): CD007868.

8. Beiswanger BB, Gish CW, Mallatt ME. A three-year study of the effect of a sodium fluoride-silica abrasive dentifrice on dental caries. Pharmacol Ther Dent. 1981;6(1-2):9-16.

9. Hirose $\mathrm{M}$, et al. Fluoride retention in saliva following toothbrushing using different types of fluoridated dentifrices containing 1500 ppmF of $\mathrm{NaF}$ and MFP. Ped Dent J. 2015;25(2):45-9.

10. Creeth JE, et al. In situ efficacy of an experimental toothpaste on enamel rehardening and prevention of demineralisation: a randomised, controlled trial. BMC Oral Health. 2020;20(1):118.

11. Attin T, Hellwig E. Salivary fluoride content after toothbrushing with a sodium fluoride and an amine fluoride dentifrice followed by different mouthrinsing procedures. J Clin Dent. 1996;7(1):6-8.

12. Campus G, Lallai MR, Carboni R. Fluoride concentration in saliva after use of oral hygiene products. Caries Res. 2003;37(1):66-70.

13. Issa Al, Toumba KJ. Oral fluoride retention in saliva following toothbrushing with child and adult dentifrices with and without water rinsing. Caries Res. 2004;38(1):15-9.

14. Arnold WH, Dorow A, Langenhorst S, Gintner Z, Bánóczy J, Gaengler P. Effect of fluoride toothpastes on enamel demineralization. BMC Oral Health. 2006;6:8.

15. Chestnutt IG, Schafer F, Jacobson AP, Stephen KW. The influence of toothbrushing frequency and post-brushing rinsing on caries experience in a caries clinical trial. Community Dent Oral Epidemiol. 1998;26(6):406-11.

16. Nazzal H, Duggal MS, Kowash MB, Kang J, Toumba KJ. Comparison of residual salivary fluoride retention using amine fluoride toothpastes in caries-free and caries-prone children. Eur Arch Paediatr Dent. 2016;17(3):165-9.

17. Duckworth RM, Morgan SN. Oral fluoride retention after use of fluoride dentifrices. Caries Res. 1991;25(2):123-9.

18. Scottish Intercollegiate Guidelines Network. 2014. Dental Interventions to Prevent Caries in Children: A national clinical guideline. [SIGN 138]. [Online] Edinburgh: Scottish Intercollegiate Guidelines Network. https://www.scott ishdental.org/wp-content/uploads/2014/04/SIGN138.pdf. Accessed 12 Oct 2021.

19. Twetman S. Caries prevention with fluoride toothpaste in children: an update. Eur Arch Paediatr Dent. 2009;10(3):162-7.

20. Reich $\mathrm{E}$. How to measure the effects of fluoride treatments in clinical trials? The role of caries prevalence and caries assessment. Caries Res. 2001:35(Suppl 1):34-9.

21. Twetman S. Prevention of dental caries as a non-communicable disease. Eur J Oral Sci. 2018;126(Suppl 1):19-25.

22. Parnell C, O'Mullane D. After-brush rinsing protocols, frequency of toothpaste use: fluoride and other active ingredients. Monogr Oral Sci. 2013;23:140-53.

23. Ekstrand KR. High fluoride dentifrices for elderly and vulnerable adults: does it work and if so, then why? Caries Res. 2016;50(Suppl 1):15-21.

24. Naumova EA, et al. Fluoride bioavailability in saliva and plaque. BMC Oral Health. 2012:12:3.

25. Tenuta LMA, Cury JA. Laboratory and human studies to estimate anticaries efficacy of fluoride toothpastes. Monogr Oral Sci. 2013;23:108-24.

26. Toumba KJ, et al. Guidelines on the use of fluoride for caries prevention in children: an updated EAPD policy document. Eur Arch Paediatr Dent. 2019;20(6):507-16.

27. Mystikos C, Yoshino T, Ramberg P, Birkhed D. Effect of post-brushing mouthrinse solutions on salivary fluoride retention. Swed Dent J. 2011;35(1):17-24.

28. Creeth J, Zero D, Mau M, Bosma ML, Butler A. The effect of dentifrice quantity and toothbrushing behaviour on oral delivery and retention of fluoride in vivo. Int Dent J. 2013;63(Suppl 2):14-24.

29. Bruun C, Givskov H, Thylstrup A. Whole saliva fluoride after toothbrushing with $\mathrm{NaF}$ and MFP dentifrices with different $\mathrm{F}$ concentrations. Caries Res. 1984;18(3):282-8. 
30. Priyadarshini Sh, Raghu R, Shetty A, Gautham P, Reddy S, Srinivasan R. Effect of organic versus inorganic fluoride on enamel microhardness: an in vitro study. J Conserv Dent. 2013;16(3):203-7.

31. Sensabaugh C, Sagel ME. Stannous fluoride dentifrice with sodium hexametaphosphate: review of laboratory, clinical and practice-based data. J Dent Hyg. 2009;83(2):70-8.

32. ten Cate JM, Featherstone JD. Mechanistic aspects of the interactions between fluoride and dental enamel. Crit Rev Oral Biol Med. 1991;2(3):283-96.

33. Toumba KJ, Curzon ME. A clinical trial of a slow-releasing fluoride device in children. Caries Res. 2005;39(3):195-200.

\section{Publisher's Note}

Springer Nature remains neutral with regard to jurisdictional claims in published maps and institutional affiliations.

- fast, convenient online submission

- thorough peer review by experienced researchers in your field

- rapid publication on acceptance

- support for research data, including large and complex data types

- gold Open Access which fosters wider collaboration and increased citations

- maximum visibility for your research: over $100 \mathrm{M}$ website views per year

At BMC, research is always in progress.

Learn more biomedcentral.com/submissions 